\title{
EXPANSÃO TÉRMICA DOS REVESTIMENTOS ODONTOLógICOS: SUA EXPLICAÇÃO POR UM PROCESSO GEOMÉTRICO
}

\begin{abstract}
SINOPSE
Aplicando os ensinamentos de uma pesquisa bibliográfica, associados à uma demonstração prática, os autores procuraram relacionar a expansão térmica dos revestimentos odontológicos a um processo geométrico de ocupação relativa de espaço, pelos diferentes corpos sólidos, segundo sua forma externa, para fins de aplicação como meio de ensino e apredizado em Departamentos de Materiais Dentários.
\end{abstract}

\section{INTRODUÇAO}

No setor de Ensino de Materiais Dentários, em vários de seus capítulos, muitas vêzes, depara o Professor com dificuldades em encontrar uma fórmula clara e convincente para explicar aos seus alunos, os diversos fenômenos de ordem física, química ou mecânica que ocorrem
Professor Dr. Léo Werner Süffert* Euclides Lniz de Oliveira, C. D. **

em diversos materiais de uso odontológico.

Dentre êsses capítulos, o que maior complexidade apresenta, com relação aos fenômenos de ordem física, se encontra aquêle referente aos revestimentos odontológicos, no que se refere à sua expansão térmica ou higroscópica; assuntos ainda, hoje, objeto de inúmeros estudos, tal a importância que encerram no campo dos Materiais Dentários.

Diante de argumentos como os acima enumerados e, visando contribuir para que assunto de tanto interêsse, tivesse acrescido à sua literatura, mais um auxílio de que o Professor de Odontologia pudesse lançar mãos, para o seu ensino e apredizado; decidimo-nos adaptar o conceito geométrico de ocupação relativa de espaço, pelos corpos sólidos de diversas formas geométricas, para uma explicação mais racional, da expansão térmica dos revestimentos odontológicos.

* Orientador, Chefe do Dep. Materiais Dentários da FO/UFRGS.

** Estagiário do Departamento de Mat. Dentários da FO/UFRGS.

R. Fac. Odont. P.A.

12: $109-116,1970$ 


\section{CONCEITO GEOMETRICO DE OCUPAGTO RELATIVA DE ESPAÇO PELOS SóLIDOS}

Segundo as definições mais elementares de Física (1), duas moléculas ou dois átomos, não podem ocupar simultâneamente, o mesmo lugar no espaço e a variação de volume dos corpos, é consequiência da variação de volume dos espaços intermoleculares e inter-atômicos.

Nos corpos cristalinos, as moléculas se confundem com os próprios cristais da substância considerada e, a variação de volume dêsses corpos, pelos mais diversos fenômenos de ordem física, é conseqüência imediata da variação dos espaços intercristais, decorrente da transformação da forma cristalina fundamental, como veremos a seguir.

Sabemos dos ensinamentos básicos de Geometria, mesmo os mais rudimentares, que a ocupação relativa de espaço por um conjunto de corpos de mesma forma geométrica e de mesmo volume, em têrmos de quantidade de espaço ocupado, depende da forma dos ditos corpos.

Sabemos ainda, que os corpos antes referidos, ocuparão, em sentido relativo, um espaço tanto maior, quanto maior fôr o número de faces apresentado por cada corpo do conjunto, isto é, quanto mais cada corpo tender para a forma esférica.

Partindo da afirmação acima, pode-se deduzir que o espaço relativo ocupado por um conjunto de corpos de mesma forma geométrica e de mesmo volume, será tanto maior quanto mais cada corpo do conjunto tender para a forma esférica.

\section{REVESTIMENTO DE USO ODON- TOLOGICO: CONCEITO E DEFINIÇã O}

Segundo Peyton et alii (2), «revestimento odontológico é um material refratário constituído de ślica na proporção de 60 a $65 \%$, em média e de gêsso, na proporção de 30 a $35 \%$, mais corantes, estabilizadores, modificadores e impurezas, em pequenas porcentagens».

Entretanto, se nos ativermos aos trabalhos de Braeseo (3), Souder \& Hidnert (4), Sweeney \& Paffenbarger (5), Soleman (6), Sosman (7) e Skinner (8), entre outros, veremos que a expansão térmica dos revestimentos odontológicos é decorrência imediata das transformações (tanto em formas como em sub-formas) alotrópicas, sofridas pelo componente refratário do revestimento, que é a sílica.

Outrossim, pesquisadores mais antigos, como Von Lasalaux, citado por Searle (9) e Saz (10), entre outros e, pesquisadores mais recentes como Searle (9) Van Vlack (11) e Etherringhton (12), nos mostram através de seus trabalhos, que a sílica ao sofrer a ação do calor, apresenta, segundo a quantidade do mesmo, transformações na sua estrutura cristalina, que são as chamadas formas e sub-formas alotrópicas, denominadas de: alfa (forma estável), quando na na temperatura ambiente e de beta (forma estável), quando sob ação do calor, respectivamente. 
Os mesmos autores antes citados, nos mostram que a sílica ao sofrer estas transformações alotrópicas e ao passar de uma forma fundamental alfa, para beta quartzo; de alfa para beta tridimita e alfa para beta cristobalita, apresenta um aumento progressivo do número de faces dos cristais Lormados, tendendo, portanto, para a forma esférica, na forma mais avançada.

Mas se fizermos uma regressão (13, 14, 15), verificaremos que a forma inicial alfa quartzo (sílica-refratário), tem forma tetraedral, isto é, quatro faces em seus cristais e que a beta cristobalita, possui forma hexagonal, isto é, seis faces, verificaremos que tendem para a forma esférica.

Portanto, julgamos poder, a partir dêstes subsidios, executar nossa proposição inicial, ou seja, nos uti- lizarmos de um processo geométrico, para justificar a expansão térmica dos revestimentos odontológicos, como meio de ensino e apredizado em Departamentos de Materiais Dentários.

\section{JUSTIFICATIVA GEOMETRICA}

Confeccionamos inicialmente oito cubos, cada um dos quais apresentava $5,5 \mathrm{~cm}$ de lado e, conseqüentemente, um volume de $166,4 \mathrm{~cm}^{3}$. (Fig. $1)$.

Confeccionamos ainda uma caixa de vidro (Fig. 2), cujo volume interno era igual à soma dos volumes dos oito cubos, ou seja $1.331 \mathrm{~cm}^{3}$. Ao colocarmos os oito cubos dentro da caixa de vidro, veremos que os mesmos preenchem ferfeitamente o espaço interno da caixa. (Fig. 3).

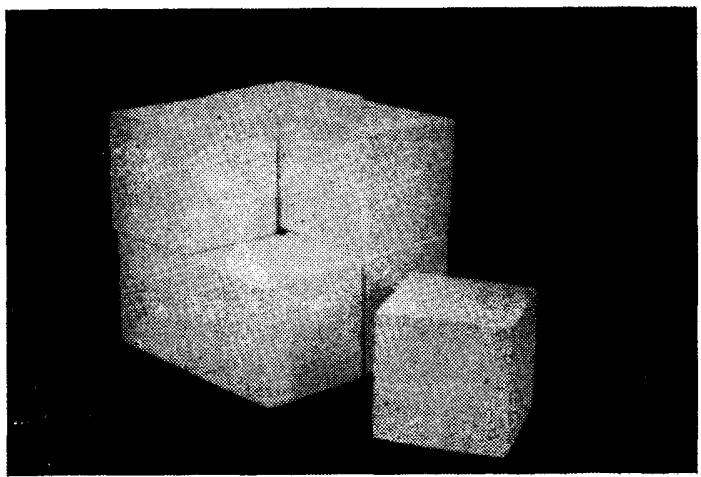

Fig. 1 


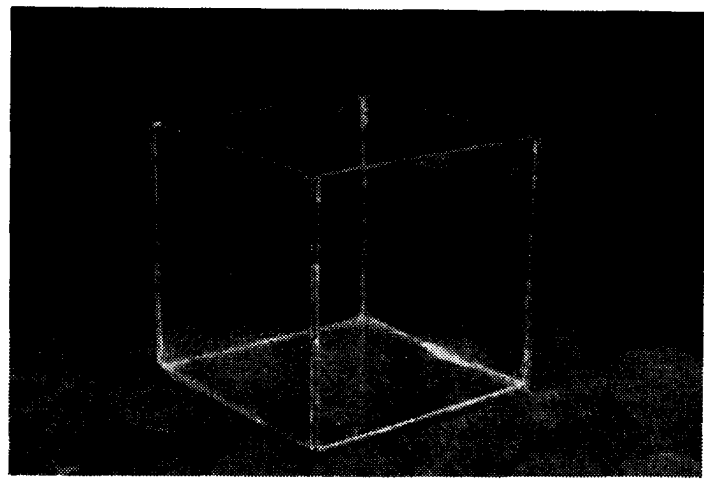

Fig. 2

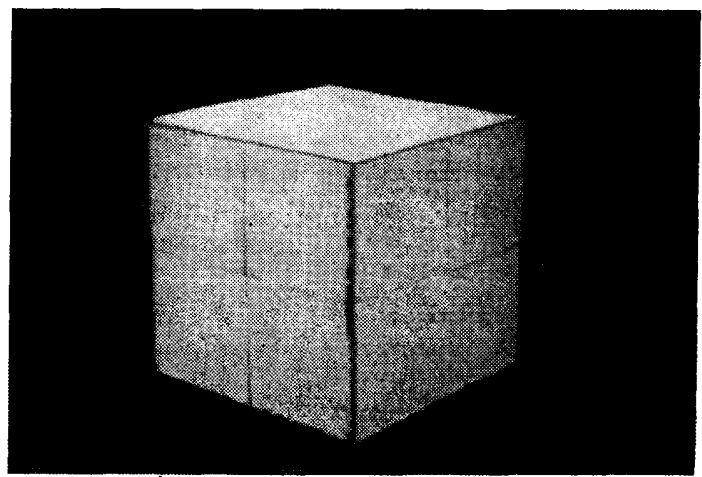

Fig. 3

Feito isso, elaboramos oito esferas de volumes iguais e os mais aproximados possíveis dos volumes dos cubos mencionados. No caso, com um raio de $3,4 \mathrm{~cm}$ e, conseqüentemente, um volume de $164,2 \mathrm{~cm}^{3}$. (Fig. 4). O volume total dos oito cubos é de $1.331 \mathrm{~cm}^{3}$ e o volume total das esferas é de 1.313,6 $\mathrm{cm}^{3}$.

Ao tentarmos colocar as oito esferas na caixa de vidro, iremos constatar que as esferas, embora com menor volume total que os cubos e volume unitário aproximado (Fig. 5), não cabem na caixa de vidro. (Fig. 6). 


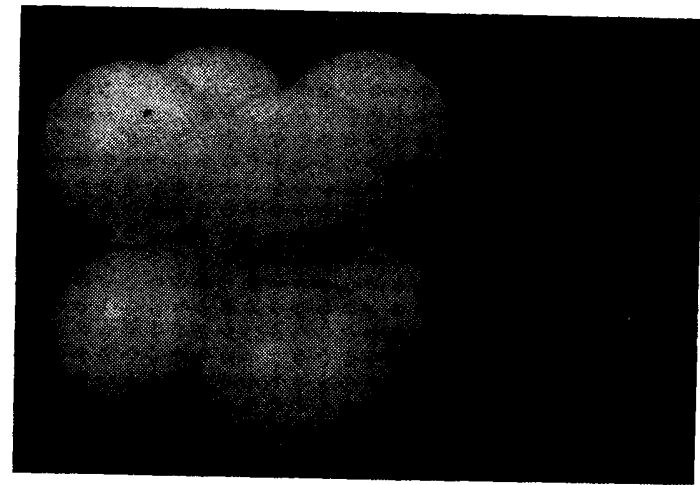

Fig. 4

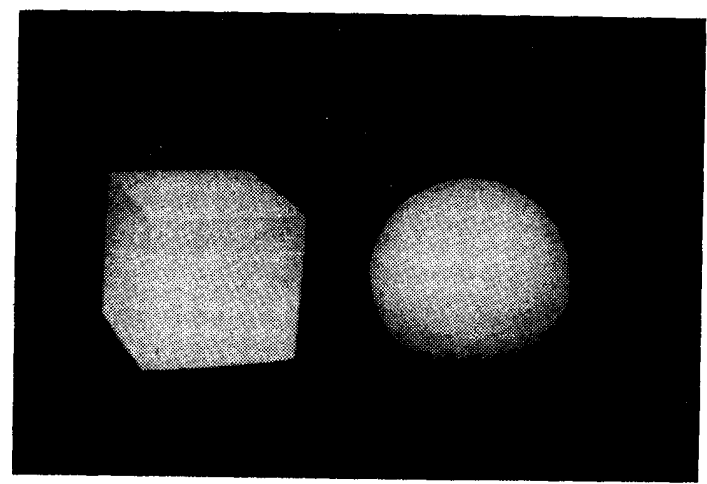

Fig. 5

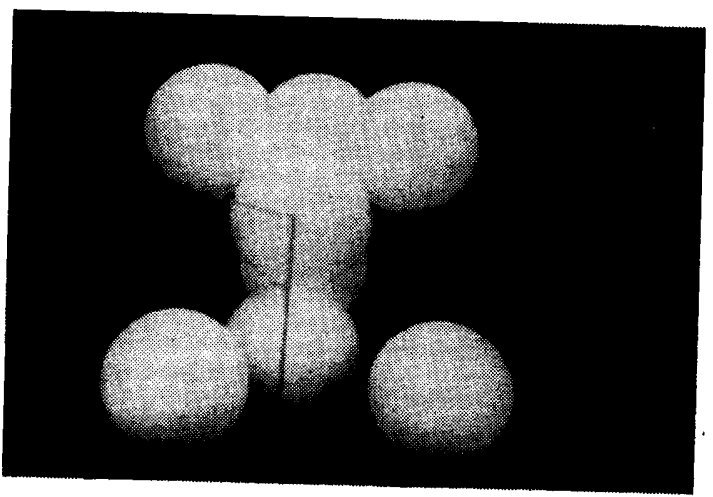

Fig. 6

R. Fac. Odont. P.A. 
Isto nos esclarece, que ao passar da forma cúbica para a forma esférica, os corpos passaram a ocupar um espaço relativo maior, isto é, em conjunto passaram a ter maior volume relativo, embora com maiores e mais numerosos espaços entre si, o que não acontecia na forma cúbica.

\section{APLICAÇão do MÉTOdO GEOMÉ- TRICO AOS REVESTIMENTOS ODONTOLógICOS}

Como já foi visto, a sílica ao sofrer a ação do calor, sofre transformações alotrópicas e passa de cristais de forma tetraedral, para cristais de formas mais complexas e com maior número de faces, tendendo para a forma esférica.

Se compararmos as duas premissas, a dos cubos e a das esferas com as transformações alotrópicas, veremos que se cncontram na mesma dependência de fatôres geométricos de ocupação relativa de espaço, embora as ações físicas determinantes, sejam de natureza diferente.

Todavia, com o já esclarecido, mais fácil se torna aplicarmos aos revestimentos odontológicos, o que foi dito para os cubos e esferas; posto que, a sílica ao passar de uma forma alotrópica fundamental para outra mais alta, sob a ação do calor, aumentando o número de faces de seus cristais, tende para forma esférica $(13,14,15)$, e passa a ocupar um maior espaço relativo, tendo como conseqüência, em virtude da não limitação de espaço ocupado, um aumento relativo da massa de revestimento.
Porém, veremos ainda, que aumentando a ocupação de espaço relativo, a mesma quantidade de revestimento passa a possuir menor densidade específica, apresentando conseqüentemente, maiores e/ou mais numerosos espaços inter-cristais (Fig. 4).

Se quisermos ser mais extensos, veremos que a expansão verificada em outras estruturas cristalinas, também segue o mesmo conceito, embora em maior complexidade, sem deixarmos de considerar outros fatôres estruturais de ordem física $e$ química, que aí ocorrem, relacionados com a densidade $e$ a movimentação atômica (11).

Entretanto, quando tratarmos de ligas metálicas ou metais, devemos ter a precaução de fazermos perfeita distinção entre expansão e dilatação, fenômenos paralelos e diferentes, visto que a primeira é permanente e a segunda reversível.

\section{observậ̃ES E CONCLUSÕES}

Segundo as pesquisas bibliográficas e a parte prática constante do presente trabalho, verificamos que:

a - A expansão térmica dos revestimentos odontológicos está na dependência do componente refratário que é a sílica;

b - Que ao sofrer a ação do calor, a sílica sofre transformações alotrópicas, com aumento do número de faces de seus cristais;

c - Que os corpos geométricos, ao 
tenderem para a forma esférica, passam a ocupar maior espaco relativo;

d - Que ao tenderem para a forma esférica, os cristais do refratário do revestimento (sílica), determinam maiores e/ou mais numerosos espaços na massa do revestimento, diminuindo sua densidade relativa e aumentando o seu volume; sendo-nos lícito concluir que:

1 - Tendo em vista os fatôres antes enumerados, pode-se, perfeitamente, aplicar um processo geométrico para explicar a expansão térmica dos revestimentos odontológicos, para fins de ensino $\theta$ aprendizado em Departamentos de Materiais Dentários, como se fêz.

\section{RESUMO}

A partir de pesquisa bibliográfica e demonstração prática os autores procuraram relacionar o fenômeno da expansão térmica dos revestimentos odontológicos por um frocesso geométrico, como método de ensino e aprendizado em Materiais Dentários.

Procuraram ainda demonstrar que a expansão térmica em revestimentos odontológicos, segue o mesmo processo de ocupação relativa de espaco ros demais corpos sólidos, pelas transformações alotrópicas sofridas nos cristais do mesmo. Como conseqüência haverá o aparecimento de maiores e/ou mais numerosos espaços entre os cristais, com a diminuição da densidade específica e aumento de volume da massa de revestimento.

\section{REFERENCIAS BIBLIOGRÁFICAS}

1 - BRAMES, R. Mineralogia. 2.ed. Barcelona, Labor, 1935.208 p.

2 - BRESEO, P. Etude des points de transformation par un méthode dilatomètrique. Annales de physique, Paris, 14: 6, 1920 (Microfilme).

3 - COLEMAN, R. L. Physical roerties of dental materials (Gold allois and acessory materials) Washington, National Bureau of Standards. Dec. 1928. Research paper $n^{\circ} 32$. p. 917-38.

4 - DECOURT, P. Elementos de mineralogia e de geologia. 2.ed. São Paulo, Melhoramentos, 1937. 671p.

5 - ETHERringhton, H. G. Modern furnace technology. 5. ed. London, Charles Griffin, 1961. 569p.

6 - NoBre, F. R. Tratado de física elementar. 23.ed. Porto, Lello, 1934. 809 p.

7 - OLIVEIRA, E. L. Silica e suas variedades alotrópicas; contribuição ao estudo de seu uso em odontologia. Rev. Fac. Odont. P. Alegre, 7: 39-58, 1965 . 
8 - PEYTON, F. A. et alii - Restorative dental materials. St. Louis, Mosby, 1960. 542p.

9 - SAZ, E. Analis quimico mineral; analis qualitativa. 2.ed. Barcelona, Tip. Casal. v.1.

10 - SEARLE, A. B. Regractory materials; their manufacture and use. London, Charles Griffin, 1940.

11 - Skinner, E. W. \& PHILLIPS, R. W. The science of dental materials. 5.ed. Philadelphia, Saunders, 1960. $635 \mathrm{p}$.

12 - SOSMAN,' R. B. The properties of silica. New York, Chemical Cathalogue, 1927. p.41-60.

13 - SOUNDER, W. \& HIDNERT, P. Measurement on the thermal expansion of fused sílica. Washington, National Bureau of Standards, 1920. Scientific paper $n^{\circ} 624$.

14 - SWEENEY, W. T. \& PAFFENBARGER, G. C. Dental casting theory and practice. Journal of Dental Research, Chicago, 5: Oct., 1931.

15 - VAN VLACK, L. H. Elements of materials science. 2.ed. Massachussets and Palo Alto, London, Addison-Wesley, 1964. 445p.

R. Fac. Odont. P.A. 